\title{
Bio-Esthetic Restoration: A Novel Approach in Conservative Dentistry
}

\section{Mittal $\mathbf{N}^{*}$ and Swain $\mathbf{G}$}

Faculty of Dental Sciences, Institute of Medical Sciences, Banaras Hindu University, Varanasi, Uttar Pradesh, India

*Corresponding author: Neelam Mittal, Former Dean and Head, Faculty of Dental Sciences, Institute of Medical Sciences, Banaras Hindu University, Varanasi, Uttar Pradesh 221005, India, Tel: 919415203360; E-mail: neelammittal@hotmail.com

Rec date: May 15, 2014, Acc date: Jun 23, 2014, Pub date: Jun 25, 2014

Copyright: ( 2014 Mittal and Swain. This is an open-access article distributed under the terms of the Creative Commons Attribution License, which permits unrestricted use, distribution, and reproduction in any medium, provided the original author and source are credited

\begin{abstract}
Fracture of anterior teeth due to trauma is the most frequent type of injury affecting permanent dentition. Despite the availability of a wide range of restorative materials, none could match the properties of natural tooth structure like translucency, wear resistance, and color stability. Hence fragment re-attachment is an excellent method of restoring fractured teeth. When the fractured fragment of the patient's tooth is not available, segment of an extracted tooth from tooth bank can be used as an alternative. In this case study, tooth \#11 revealing Ellis' Class II fracture was restored by fragment re-attachment method using an extracted tooth. Extracted tooth of matching shade was selected from the tooth bank, cut in accordance with the fractured portion, and attached using composite resin. At 1 year follow up, the restoration revealed good aesthetic, functional and psychosocial results, justifying the use of this technique to achieve the morpho-functional recovery of extensively damaged teeth.
\end{abstract}

Keywords: Biological restoration; Esthetics; Re-attachment; Tooth fracture

\section{Introduction}

Fracture of anterior teeth by trauma is the most frequent type of injury affecting the permanent dentition, especially in children between 9 and 11 years of age. The most frequently affected teeth are the maxillary central incisors owing to their anterior position and protrusion caused by eruptive process [1].

During the last century, clinicians utilized a variety of procedures (eg., pin retained resin, orthodontic bands, modified three-quarter crown, full coverage gold with bonded porcelain, porcelain jacket crown, porcelain bonded crown and porcelain inlays) for the restoration of fractured crown [2]. Chosack and Eidelman, in 1964, proposed the restoration of fractured crown by reattachment using the dental fragment [3].

Restoration using natural tooth fragment is known as "Biological Restoration". The expression "biological restoration" was coined in 1991 by Santos and Bianchi [4]. When the fractured fragment of the patient's own tooth is reattached, it is referred to as autogenous bonding [5] while homogenous bonding refers to the use of extracted teeth to prepare crowns or posts [6].

This technique offers several advantages over other techniques used for restoring fractured teeth. It is a conservative and an immediate restorative procedure. It provides total aesthetic recovery because of the natural tooth contour, color, translucency, and surface texture provided by the reattached fragment [7]. It also provides color stability over time and the rate of wear is similar to other natural teeth [8].

Moreover, trauma to oral structures like teeth poses a great psychological impact on the minds of patients and reattaching patients' own fragment may reduce this impact [9]. The clinical procedure is safe and simple; therefore, requiring less chairside time, which might reduce the cost of the treatment [7]. Thus, reattachment can be a line of treatment for crown root fracture cases.
When the patient doesn't present with the fractured fragment or its use is not recommended, donated extracted teeth (homogenous bonding) can be used for re-attachment procedure [6]. Following case report presents the management of crown fracture using homogenous bonding technique.

\section{Case Presentation}

A 25 year old male patient reported to the Dental department of Sir Sunderlal Hospital, BHU, with the chief complaint of broken upper front tooth due to history of trauma 6 months back. The clinical and radiographic examination revealed an Ellis' Class II fracture in relation to tooth\# 11 (Figure 1). Tooth \#11 was vital on vitality test.

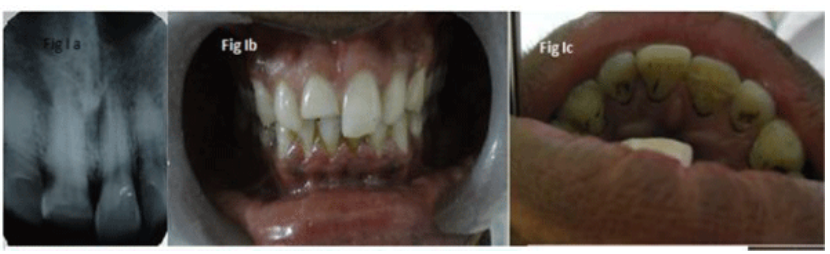

Figure 1: a) Pre-operative IOPA radiograph of fractured tooth \#11, b,c) Pre-operative photograph of fractured tooth\#11 labially and palatally

As tooth was vital restoration by aesthetic restorative material was planned. Composite restoration is the choice of treatment for the patient but in this patient we tried biological restoration as an alternative. The patient did not have the fractured fragment of the tooth homogenous bonding was planned for restoring the fractured tooth.

Before treatment procedure ethical clearance was taken from the Ethical committee, Faculty of medicine, IMS, BHU. The treatment plan was explained to the patient and the consent was taken. Selective grinding of sharp edges of the fractured tooth was done and its shade 
was determined using a shade guide. Impressions of maxillary and mandibular arch of the patient were made with silicon impression material and poured with dental stone for fabricating casts required for restoration adjustment. Single rooted tooth of shape and size similar to damaged tooth were selected from toothbank for restoration. The extracted donated tooth was scaled, soft tissue tags and periodontal remnant removed before the tooth was stored in the tooth bank. Colour matching of the damaged tooth is done with the homogeneous tooth, sterilized by immersing in $0.9 \mathrm{~N} \mathrm{NaOH}$ for 2 hours and then autoclaving at $121^{\circ} \mathrm{C}$ for 15 minutes.

Mesiodistal, cervico-occlusal and buccolingual dimensions of the tooth were measured using a compass. Articulating paper was then used to demarcate the areas that needed further adjustments. Coronal part of the donor tooth was cut with diamond disk according to the shape and size of fractured tooth. Adjustments were done on the cut fragment and re-evaluated using the maxillary cast on articulator. Fragment was intentionally kept a little larger than the required size to provide for the final adjustments needed to be done inside patient's mouth (Figure 2).

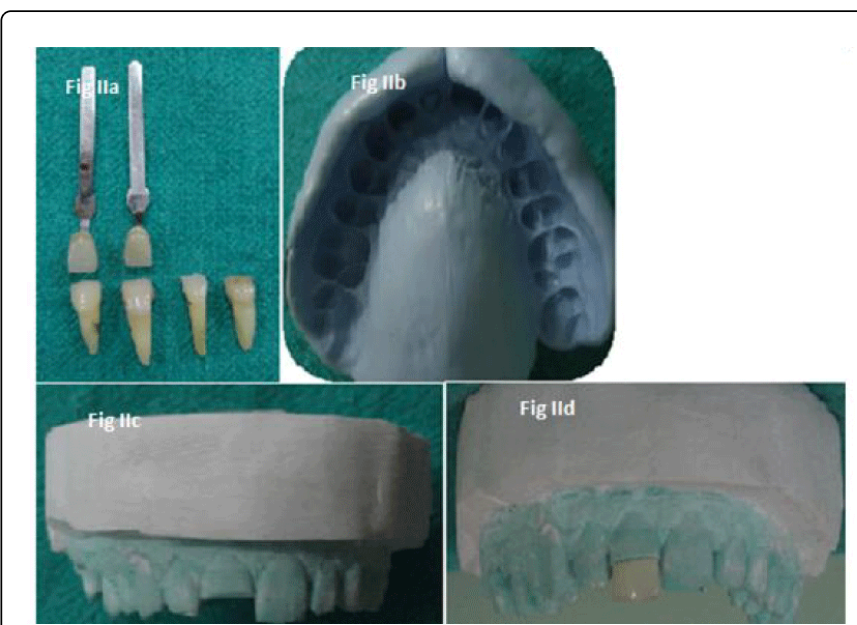

Figure 2: a) Selection of extracted tooth from tooth bank by shade matching, b) Silicon impression of fractured tooth, c) Cast of fractured tooth, d) Adjustment of segment on cast

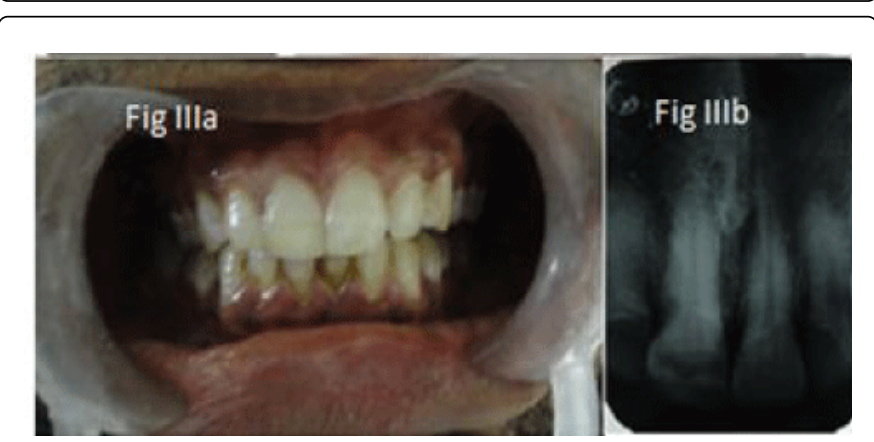

Figure 3: a) Post-operative photograph of patient after reattachment, b) Post-operative IOPA radiograph of tooth \#11

After final adjustment, acid etching of the cut tooth fragment as well as the remaining fractured tooth was carried out for 15 seconds using $37 \%$ phosphoric acid. Bonding agent (XP Bond-Universal Total- etch Adhesive, Dentsply) was subsequently applied, and the fragment was attached to the fractured tooth using a thin layer of resin (TetricN-Flow, Ivoclar Vivadent), applied on the margins of the fractured tooth and the adjusted tooth fragment, as an adhesive. The fragment was held in its proper position and the adhesive resin was light cured from both sides for 20 seconds. Thereafter, finishing and polishing was performed using diamond burs and sandpaper disks of different granulations (Figure 3).

Patient was kept on follow up and a 1 year follow up revealed good aesthetics, function and retention of the restoration (Figure 4)

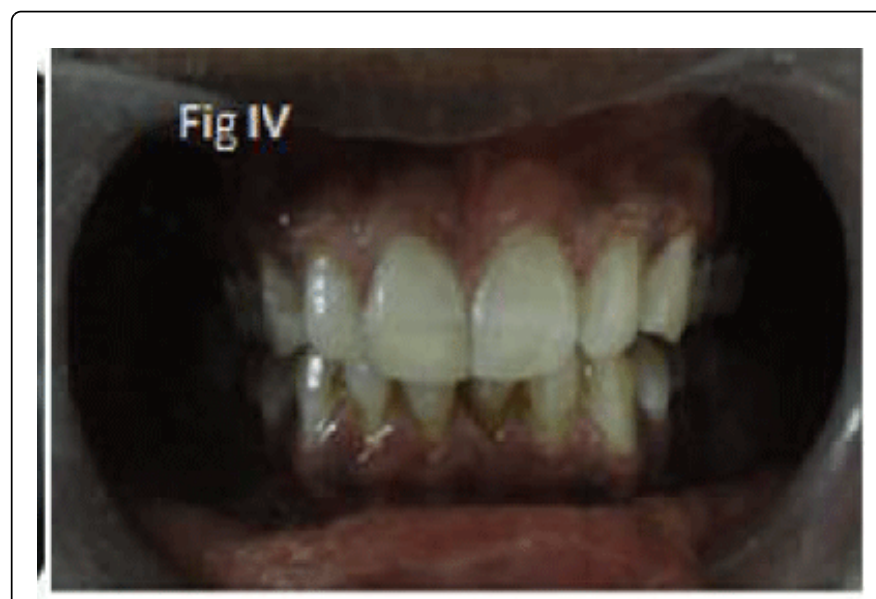

Figure 4: One year follow up photograph of patient

\section{Discussion}

Biological restoration provides an excellent mode of restoring fractured teeth. Tooth banks, providing donor teeth for biological restorations, are non-profit institutions generally integrated into teaching or research institutions. The donated teeth are sorted and stored in distilled water under refrigeration [10]. Before manipulation, the teeth are properly cleaned, stored, and sterilized by soaking in sodium hydroxide $(\mathrm{NaOH}), 0.09 \mathrm{~N}$ or $0.9 \mathrm{~N}$, for 2 hours plus autoclave at $121^{\circ} \mathrm{C}$ for 1 hour (gravity displacement sterilizer) ensuring all biosecurity standards [6,11].

Farik et al. [12] showed that most fifth-generation dentin bonding adhesives with an unfilled resin increase the fracture resistance of reattached coronal fragments with the tooth remnant. Hence in this case we have used $5^{\text {th }}$ generation bonding agent XP Bond (Dentsply) for reattachment procedure. Biological restorations not only mimic the missing part of the oral structures, but are also biofunctional having similar modulus of elasticity with fractured tooth [13]. The length of each appointment is significantly reduced because the fractured fragment from natural teeth are prepared and adjusted beforehand. Chair side time for bonding procedure of fragment is relatively short, which is a merit [6,13-15]. Resin composite restorations do not present these advantages and can allow staining and plaque formation on their surfaces.

Disadvantages of the biological restoration technique include the difficulty in obtaining teeth with the required coronal dimensions and characteristics, problems inherent to indirect restorations and matching fragment color with that of fractured tooth. Also, having fragments from other people's teeth in their mouth is not a pleasant 
Citation: Mittal N, Swain G (2014) Bio-Esthetic Restoration: A Novel Approach in Conservative Dentistry. Dentistry 4: 245. doi:

Page 3 of 3

idea for some patients and many of them refuse to receive this treatment [6]. Presently, secure methods of sterilization and storage are available to ensure safety in using teeth or tooth fragments coming from tooth banks $[6,16]$.

\section{Conclusion}

It is not the equipment, but the dentist who makes the difference. The technique for biological restoration is simple, less time consuming, allows the preservation of sound tooth structure and provides natural look compared to composite resins and stainless steel crowns, especially regarding translucency. It offers excellent esthetic, functional and psychosocial results, which justify the use of this technique to achieve the morpho-functional recovery of extensively damaged teeth. Biological restoration serves as an effective treatment alternative in restorative dentistry as it fulfills all three FDI criteria for evaluation of restoration, i.e., aesthetic, functional and biological aspects.

\section{References}

1. Bruschi-Alonso RC, Alonso RC, Correr GM, Alves MC, Lewgoy HR, et al. (2010) Reattachment of anterior fractured teeth: Effect of materials and techniques on impact strength. Dental Traumatol 26: 315-322.

2. Badami AA, Dunne SM, Scheer B (1995) An in vitro investigation into the shear bond strengths of two dentin bonding agent used in the reattachment of incisal edge fragments. Endodont Dent Traumatol 11: 129-135.

3. Chosack A, Eidelman E (1964) Rehabilitation of a fractured incisor using the patient's natural crown. Case report. J Dent Child 31: 19-21.

4. Santos J, Bianchi J (1991) Restoration of severely damaged teeth with resin bonding systems: case reports. Quintessence Int 22: 611-615.
5. Demarco FF, de Moura FR, Tarquinio SB, Lima FG (2008) Reattachment using a fragment from an extracted tooth to treat complicated coronal fracture. Dent Traumatol 24: 257-261.

6. Busato AL, Loguercio AD, Barbosa AN, Sanseverino Mdo C, Macedo RP, et al. (1998) Biological restorations using tooth fragments. Am J Dent 11: 46-48.

7. Maia EA, Baratieri LN, de Andrada MA, Monteiro S Jr, de Araújo EM Jr (2003) Tooth fragment reattachment: Fundamentals of the technique and two case reports. Quintessence Int 34: 99-107.

8. Kanca J (1996) Replacement of a fractured incisor fragment over pulpal exposure: A long-term case report. Quintessence Int 27: 829-832.

9. Chaugule V, Bhat C, Patil V, Mithiborwala SH (2009) Reattachment of a vertical complicated subgingival crown root fracture in a 10 year old child: A case report. Int J Clin Pediatr Dent 2: 53-59.

10. Nassif AC, Tieri F, Ana PA, Botta SB, Imparato JCP (2003) Structuralization of a human teeth bank. Pesqui Odontol Bras 17: 70-74.

11. Rutala WA, Weber DJ (2010) Guideline for Disinfection and Sterilization of Prion-Contaminated Medical Instruments.

12. Farik B, Munksgaard EC, Andreasen JO, Kreiborg S (2002) Fractured teeth bonded with dentin adhesives with and without unfilled resin. Dent Traumatol 18: 66-69.

13. Kapur A, Chawla HS, Goyal A, Gaube K (2005) An esthetic point of view in very young children. J Clin Pediatr Dent 30: 99-103.

14. Barcelos R, Neves AA, Primo L, Souza IPR (2003) Biological restorations as an alternative treatment for primary posterior teeth. J Clin Paediatr Dent 27: 305-310.

15. Ramires-Romito ACD, Wanderley MT, Oliveira MDM, Imparato JCP, Côrrea MSNP (2000) Biologic restoration of primary anterior teeth. Quintessence Int 31: 405-411.

16. Yang ZP, Chang CS (1990) A 3 year follow-up of a homo transplanted tooth from a tooth bank. J Endod 16: 34-37. 